infant makes great effort to avoid the covering hand so that he can maintain vision on the object of interest. When the eye with poor vision is covered no such avoiding movements are made since the infant is in no wi inconvenienced by the test.

Although this screening examination may be carried out by doctors it is much sore readily and accurately performed by 0 .1optists, whose training and abilities with young children are specifically designed to thi $\sim n d$. Dr Valman's statement that if a squint is seen or suspected at any time after 6 months of age the child should be examined by an ophthalmologist is correct; but in the present state of undermanning in the ophthalmological services of the NHS there is an excellent case to be made out for such initial screening to be carried out by orthoptists, and only those vision in one eye by the orthoptist should be referred on to the ophthalmologist.

Peter Fells

Moorfields Eye Hospital,
London ECIV 2PD

\section{Vitamin $\mathbf{D}_{3}$ in osteoporosis}

SIR,-Professor B E C Nordin and his colleagues have reported (16 February, $p$ 451) that $1 \alpha$-hydroxycholecalciferol $\left(1 \propto \mathrm{OHD}_{3}\right)$ is of no use when given alone for the treatment of spinal osteoporosis in postmenopausal women. We have studied the effects of 1-hydroxylated vitamin $\mathrm{D}_{3}\left(1-\mathrm{OHD}_{3}\right)$ preparations in a group of patients with osteoporosis.

Five men and twenty women with back pain and no biochemical evidence of osteomalacia took part in the study. Each was allocated randomly either to a group receiving from 0.5 to $1.0 \mathrm{mg}$ of $1-\mathrm{OHD}_{3}$ daily for six months (seven patients received $1,25(\mathrm{OH})_{2} \mathrm{D}_{3}$ and eight received $\left.1 \propto \mathrm{OHD}_{3}\right)$ or to a group (1n patients) receiving $0.5 \mathrm{ml}$ daily of a placebo. Eleven patients entering the 1-OHD group and nine entering the placebo group had two or more vertebral compression fractures and the average ages $( \pm S D)$ of the patients in the groups were $69.9( \pm 9.8)$ years and $73.0( \pm 8.6)$ years respectively. An iliac crest biopsy was taken from every patient assigned to the $1-\mathrm{OHD}_{3}$ group; none of the biopsies showed evidence of osteomalacia.

All patients were followed up for at least six months. Results from the study showed that intestinal calcium absorption, as assessed by a double isotope technique, rose significantly (paired $t$ test $\mathrm{p}<0.005$ ) in the $1-\mathrm{OHD}_{3}$ group, but so did urinary calcium excretion (paired test $\mathrm{p}<0.05)$. Neither changed significantly in the placebo group. The incidence of new vertebral compression fractures was the same $(20 \%)$ in both the $1-\mathrm{OHD}_{3}$ and the placebo groups, and the values for bone mineral mass per unit length estimated by photon absorptiometry ${ }^{1}$ of the righ femur and right radius and ulna did not change significantly (paired $t$ test) in either group over the six months. Back pain and mobility were assessed from the patients' spontaneous comments and by inquiries into analgesic consumption Eleven of those receiving $1-\mathrm{OHD}_{3}$ and one of those receiving placebo considered that their back pain was improved; seven receiving 1-OHD but none receiving placebo considered mobility infants who are suspected of a squint or poor

improved (see accompanying table). Comparing the responses in the two groups in terms of im proved versus not improved for severity of back pain and mobility the Fisher exact test gives probabilities of 0.004 and 0.02 .

The study provided no objective evidence of improved bone strength and its single-blind design makes the interpretation of symptomatic improvement uncertain. The findings do, however, raise the possibility that the 1-hydroxylated vitamin $\mathrm{D}_{3}$ preparations produced improvement in the symptoms of some of the patients in the $1-\mathrm{OHD}_{3}$ group.

I WANDLESS S JARVIS

J GRIMLEY EVANS EDwin G A AIRD J STEVENS

Newce.sile General Hospital and University of Newcastle upon Tyne,

${ }^{1}$ Aird 3GA, Pierides AM. Br $\mathcal{F}$ Radiol 1977;50:350-6.

\section{Cholesterol and mortality rates}

SIR,-In New Zealand Maoris, Dr Robert Beaglehole and others (2 February, p 285) noted an inverse relation between serum cholesterol level and overall mortality, and mortality from cancer and "other" causes of death. Hence the authors warned against introducing measures to reduce cholesterol level to ameliorate cardiovascular disease which in these people has an incidence as high as or even higher than that in New Zealand whites. Conceivably, such measures might worsen Maoris' total mortality rate, since "the risk ratios of total mortality at a serum cholesterol concentration of $4.14 \mathrm{mmol} /$ $(160 \mathrm{mg} / 100 \mathrm{ml})$, as compared with that at a concentration of $6.73 \mathrm{mmol} / 1(260 \mathrm{mg} / 100 \mathrm{ml})$, when adjusted ... were 1.7 for men and 1.4 for women." The authors commendably urged caution in applying their findings on Maoris to other populations.

In the Maori population the lower and uppe serum cholesterol values chosen $(4 \cdot 14$ versus $6 \cdot 73$ $\mathrm{mmol} / \mathrm{l}$ ) are very wide apart. The point we wish to make is that serum cholesterol and mortality associations, when significant, will vary from population to population, in part because the mean cholesterol level of myocardial infarction patients varies considerably - from $7.2 \mathrm{mmol} / 1(278 \mathrm{mg} / 100$ $\mathrm{ml})$ in Australia ${ }^{1}$ to as low as $4.4 \mathrm{mmol} / 1(170 \mathrm{mg} /$ $100 \mathrm{ml}$ ) in India. ${ }^{2}$ Furthermore, the mean level in myocardial infarction patients varies widely even within a given country, as demonstrated in Italy and Norway. ${ }^{4}$ Such variation certainly will add to difficulties in investigations but does not detract from the authors' emphasis on "the importance both of studying risk factors on a population specific basis and of using total mortality as an end point for community-based intervention studies."

A further complicating factor concerns differences in reactivity displayed by different emerging populations having somewhat similar biological variables. Maoris have slightly lower cholesterol levels (about $1 \mathrm{mmol} / 1$ (38.6 mg/100 ml) less) than New Zealand whites, the same systolic pressures, but much greater frequencies of obesity in both men and women. They are, as mentioned, very

Clinical response in patients with osteoporosis taking placebo and $1-\mathrm{OHD}_{3}$

\begin{tabular}{|c|c|c|c|c|c|c|}
\hline & \multicolumn{3}{|c|}{ Severity of back pain } & \multicolumn{3}{|c|}{ Mobility } \\
\hline & Decreased & Unchanged & Increased & Decreased & Unchanged & Increased \\
\hline $\begin{array}{l}\text { No taking placebo } \\
\text { No taking } 1-\mathrm{OHD}_{3}\end{array}$ & $11(73 \%)$ & $\begin{array}{l}6 \\
4\end{array}$ & $\begin{array}{l}3 \\
0\end{array}$ & $\begin{array}{l}1 \\
0\end{array}$ & $\begin{array}{l}9 \\
8\end{array}$ & $\begin{array}{l}0 \\
7(47 \%)\end{array}$ \\
\hline
\end{tabular}

prone to cardiovascular disease. In Johannesburg, urban blacks at middle age and later have lower cholesterol levels (about 1.0-1.5 mmol/1 (38.6-57.9 $\mathrm{mg} / 100 \mathrm{ml}$ ) less) than whites but much higher diastolic and systolic pressures, and a greater frequency of obesity, principally in women. ${ }^{5}$ Yet, in remarkably striking contrast to Maoris' experience, the age-specific mortality rate of blacks from ischaemic heart disease is very low, only $5-10 \%$ or so of that of whites. ${ }^{6}$ Interestingly, this diversity of ischaemic heart disease experience of South African blacks and whites resembles that noted in immigrant Caribbeans and whites in East London.?

Dr Beaglehole and his colleagues, in stressing the use of total mortality as an end point for community-based intervention, have in a sense underlined the view of Rose and Barker ${ }^{8}$ that "the outcome of screening must be judged in terms of its effect on mortality or illness. ..."This scrutiny of the worthwhileness of intervention has long been urged by Cochrane. ${ }^{9}$ When carried to its logical conclusion this scrutiny, if its results are implemented, has enormous implications regarding many well-known practices, some especially relevant to Third World populations. The authors are to be congratulated on their thought-stimulating contribution.

A R P WALKER

South African Institute for Medical Research,

1 Palmer AJ, Blacket RB, Leelarthaepin B. Med $\mathcal{F}$ Aust 1973;2:19-23.

Chaudhuri S, Das S, Das NC. Ind Heart $\mathcal{f} 1966$;18 391-402.

Keys A, Fidanza F. Circulation 1960;22:1091-106.

Jervell A, Meyer K, Westlund K. Acta Med Scand

- Seftel HC. S Afr Med f 1978;54:99-104.

Pedoe HT, Clayton $\mathrm{A}$ (in press).j, Bridgen W, McDonald L. Lancet 1975;ii :833-8.

8 Rose G, Barker DJP. Br Med $\mathscr{f} 1978$;ii:1417-8.

- Cochrane AL. Effectiveness and efficiency. Random reflections on health services. London: Nufield
Provincial Hospitals Trust, 1972 .

\section{Massive bleeding from the large bowel}

SIR,-Your leading article (16 February, p 425) in discussing the differential diagnosis of this perplexing problem rightly stresses that known diverticular disease cannot be assumed as the source of haemorrhage. ${ }^{1}$ Your review, neglects, however, to discuss the important role played by colonoscopy. This investigation may make a significant contribution to both diagnosis and management, as has been shown by a number of studies, ${ }^{23}$ especially when barium enema or the single most useful procedure, selective mesenteric angiography, is not available.

You rightly draw attention to the greater awareness of vascular ectasias as a cause of bleeding, particularly in the elderly. Despite suggestions in the literature $e^{5-7}$ that colonoscopy is not of value in this condition, it seems logical that a mucosal defect will be present if significant blood loss has occurred and that this will be visible in the well-prepared bowel on careful scrutiny by the endoscopist. Such angiodysplastic lesions have been seen in nine patients in the last 500 colonoscopies in this hospital. The mean age of the patients was 70 and the mean haemoglobin concentration at presentation $6.9 \mathrm{~g} / \mathrm{dl}$. Two patients have been successfully operated on for multiple lesions and the other seven have had diathermy coagulation applied at colonoscopy ${ }^{8}$ without any recurrence. The diagnosis was confirmed histologically in one of the operative specimens and in six of the seven patients at diathermy coagulation biopsy. 